\title{
Analysis of Climate Change and 24-Hour Design Storm Depths for a Range of Return Periods Across South Carolina
}

\author{
Derek Hutton ${ }^{1}$, Nigel B. Kaye ${ }^{2}$, and William D. Martin III ${ }^{3}$
}

\begin{abstract}
AUTHORS: 'Graduate Student, Glenn Department of Civil Engineering, Clemson University, 104 Lowry Hall, Clemson, SC 29634, USA. ${ }^{2}$ Associate Professor, Glenn Department of Civil Engineering, Clemson University, 114 Lowry Hall, Clemson, SC 29634, USA. ${ }^{3}$ Lecturer, General Engineering Department, Clemson University, 104 Holtzendorff Hall, Clemson, SC 29634, USA.
\end{abstract}

\begin{abstract}
A warming climate leads to a moister atmosphere and more rapid hydrologic cycle. As such, many parts of the country are predicted to experience more total rainfall per year and more frequent extreme rainfall events. Most regions of the country have stormwater systems designed to a standard that matches outflow rates to predevelopment values for specified return period storms. Increases in these return period storm depths, as predicted by many global climate models, will stress existing stormwater infrastructure. This paper examines how rainfall patterns will change over the remainder of the century across the state of South Carolina.

Rainfall simulations from 134 realizations of 21 global climate models were analyzed across the state of South Carolina through 2099. Results show that there will be increases in both annual total rainfall (ATR) and 24-hour design storm depth for a range of return period storms. Across South Carolina, ATR is predicted to increase by approximately 2.3-4.0 inches over the forecast period while the 100 year design storm depth is predicted to increase by $0.5-1.2$ inches depending on location. However there are significant regional variations with the Savannah River Basin experiencing smaller increases in ATR compared to the rest of the state.
\end{abstract}

\section{INTRODUCTION}

Over the last century the average global temperature has risen 0.85 degrees Celsius (IPCC, 2014). Forecasting climate changes is important for preparing societies for possible impacts to food supply, water resources, infrastructure, ecosystems, and even human health. Temperature changes are only one aspect of the predicted changes the Earth will experience. Other changes include precipitation patterns and intensities, ice and snow cover, sea level, and ocean acidity. In 2001, the Intergovernmental Panel on Climate Change (IPCC) published strong conclusions in response to evidence of global climate change (IPCC, 2001). The 1990's were reported to be the warmest decade, for the northern hemisphere, since adequate record keeping (IPCC, 2001). Trends in precipitation are increasing slightly, about $1 \%$ per ten years, and the number of severe precipitation events is also increasing (IPCC, 2001). The IPCC concluded that the warming that is being observed in the last century is not natural. Models that attempt to predict historical trends based on natural radiation perform less well compared to models that include increases in atmospheric greenhouse gas concentrations (IPCC, 2001).

The IPCC made its conclusions based upon a large variety of research and data. Specific to the United States, there has been trend analysis done for precipitation and temperature for major urban areas. Mishra and Lettenmaier (2011) found that there were significant increases in extreme precipitation events in 30\% of urban areas from 1950-2009. Martinez et al. (2012) found increasing trends in temperature and decreasing trends for precipitation for the state of Florida for a similar time period.

In general, climate change models predict a warmer and moister atmosphere resulting in a more rapid hydrologic cycle and more extreme rainfall events. Stormwater systems, some of which are already overloaded, will be stressed even further with increased runoff. As a result water quality will decrease as sediment runoff and flooding will increase.

Current South Carolina stormwater regulations (DHEC, 2002), only regulate peak flows and not total runoff. As such, traditional stormwater designs have reduced infiltration and increased total runoff when compared to original site hydrology. Developing sites often requires significant downstream storm sewer infrastructure. With increased rainfall due to climate change, these design weaknesses will cause a disproportionate amount of the additional rainfall to directly become runoff. Responsible stormwater management is required to maintain the quality of surface water in a climate that will exhibit increased frequency and intensity of rainfall over time.

This paper presents the results of a detailed analysis of rainfall forecasts based on Global Climate Model (GCM) data 
archived through the Climate Model Inter-comparison Project - 5 (CMIP5). The data is analyzed to examine the change in annual total rainfall (ATR) and 2, 5, 10, 25, 50 and 100 year 24 hour storm depths between now and the end of the century (the storm depths selected are those used by various municipal and state agencies in their stormwater regulations).

Engineers and regulators will better understand the risk a changing climate will present to stormwater infrastructure as a result of this analysis. That is particularly true for state agencies with regulatory responsibilities for defining stormwater design events such as SC-DHEC and SC-DOT.

The remainder of the paper is structured as follows. The project description summarizes the main goals of the project and pertinent literature. The sources of data used and the analysis techniques are described in the methods section. The results section presents forecasts for the ATR and 2, 5, $10,25,50$, and 100 year 24 hour storm depths for the entire state of South Carolina. Conclusions and suggestions for future work are presented in the discussion section.

\section{PROJECT DESCRIPTION}

As an increase of rainfall intensity and frequency is expected, the responsibility of designing stormwater systems to be effective for their entire design life lies with the designing engineer. However, in order to effectively plan for future rainfall patterns, data on expected changes is required. GCM's typically produce low spatial resolution data that must be statistically downscaled for the purposes of local hydrologic trend analysis. There are a number of approaches to downscaling including Bias Corrected Constructed Analogs (BCCA) and Bias Correction and Spatial Disaggregation (BCSD) (Ahmed et al. 2013). The choice of downscaling technique depends on the application. Downscaling GCMs using Bias Corrected Constructed Analogs (BCCA) provides a higher temporal and spatial resolution (Barsugli, et al, 2009, Maurer \& Hidalgo, 2008) and improved estimates of precipitation compared to other downscaling methods (Brown \& Wilby, 2012). Using multiple GCMs removes the bias that a certain model may have and improves the estimation of variability that is typically under estimated by using a single downscaled data set (Brekke, et al., 2008). This study uses projected rainfall data from 134 realizations of GCMs with daily temporal resolution and $1 / 80$ degree spatial resolution to explore long term trends in rainfall in South Carolina. These data sets include GCM model runs for all four Representative Concentration Pathways (RCPs). That is, they include model runs for a range of different long term atmospheric CO2 concentration levels. The choice of appropriate RCP would require a prediction of future public policy which is beyond the scope of this paper. As such, all four data sets were lumped together. The results, therefore, represent an average set of predictions of future rainfall patterns. This approach may underestimate the potential changes in rainfall patterns if global CO2 emissions are not curbed.

\section{METHODS}

Downscaled GCM data was analyzed for each of the locations of NOAA precipitation measuring stations, Figure 1, so that the projected rainfall data could be directly compared to historical data and posted 24 hour storm depths. Historical rainfall data is available for all of the stations through the National Climatic Data Center (NCDC) run by NOAA. While breaks in the data (no data recorded) exist in the data sets, they only exist for relatively short periods and are not accounted for in the analysis. The average data set for the historical data from 1950-1999 contained 41.6 years of data. The list of stations was edited to remove duplicate stations (occurring for stations that measured both hourly and daily values), stations located outside the projection grid (occurring for some coastal stations), or stations with region information not specified by NOAA (Bonnin, et al., 2006). BCCA downscaled CMIP5 daily hydrologic projections were downloaded for each station from an online archive (U.S. Department of Interior, 2014). The projections used 21 climate models with various combinations of four RCPs and different realizations creating a total of 134 different daily rainfall projections for a period of record (POR) from 2015-2099.

A precipitation frequency analysis had already been performed on the historical data by NOAA and was the computational method behind the Precipitation Frequency Data Server (PFDS), which gives the storm depths for different return periods and durations. The NOAA Atlas 14, Volume 2 is based on data from 13 states and covers precipitation frequency estimates for event durations of 5 minutes through 60 days at recurrence intervals of 1-year through 1,000 years. The method is based on converting annual maximum data to partial duration data series and then further "personalizing" by location through regionalization. The analysis herein focused on 24 hour storm depths due to their role in stormwater design regulations.

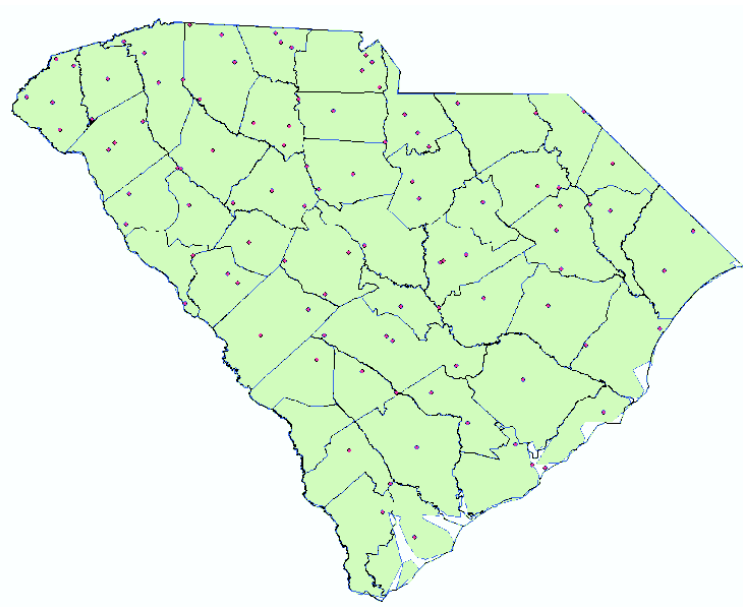

Figure 1. NOAA weather station locations in South Carolina for which observed data was collected and downscaled GCM data was analyzed. 
After importing the data for each station, the maximum daily values were converted to 24 -hour maximum values using

$$
P_{24 \max }=P_{\max } \times t_{24}
$$

where $t_{24}=1.13$ is the ratio between average daily maxima and average 24-hour maxima. This ratio is empirically derived from 86 stations that had 15 years of concurrent data. Comparing the conversion factors to past NOAA volumes and other studies finds that the conversion value is comparable if not the same. The 24 hour annual maximum depth data set was then converted to partial duration data series using

$$
P_{A A \max }=P_{24 \max } \times T_{A M S} / T_{P D S}
$$

The parameter $T_{A M S} / T_{P D S}$ is equal to 1.58 and represents the frequency ratio between an annual maximum series and a partial duration series. This ratio allows for multiple large storms in a single year be considered in the final value such as occurred in Clemson, SC in 2013. The partial duration series was averaged and converted into a set of 24 hour storm depths of specified return period using

$$
P_{n \_y r}=\bar{P}_{A A \max } \times R G F_{n}
$$

where $\mathrm{n}$ is the return period in years. The Regional Growth Factor (RGF) for each return period depends on the location of the rain gauge and is given in the NOAAAtlas. Distribution of the regions for the RGF can be seen in Figure 2. For example, since the station in Clemson, SC (Station ID 38-1770) is assigned to NOAA Region 12, its RGFs for the 2, 5, 10, 25, 50 , and 100 year storms are $0.907,1.196,1.429,1.801,2.148$, and 2.272 respectively (Bonin, et al., 2006). Using the same frequency analysis technique employed by NOAA allows for direct comparison of the GCM precipitation frequency values to the precipitation frequency values reported by NOAA based on historical rainfall data.

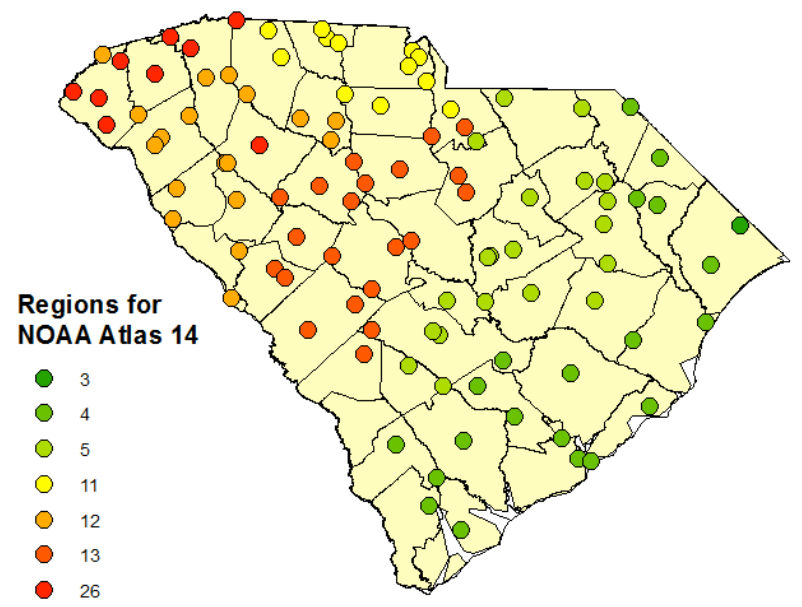

Figure 2. Regions for Stations in SC from NOAA Atlas 14.

\section{RESULTS}

Results are presented for changes in Annual Total Rainfall (ATR) and for the 24 hour storm depth for 2, 5, 10, 25, 50, and 100 year return period storms. Because much of the data presented is location specific, Clemson, $\mathrm{SC}$ was chosen as a case study and is represented in many of the figures herein to illustrate a typical location. There are also figures that summarize this data for the entire state of South Carolina.

\section{Changes in annual total rainfall}

For each NOAA precipitation gauge location the daily time series of historical rainfall data and each downscaled GCM data set was converted into an ATR time series. A plot of the 134 ATR time series from 2015-2099 along with the historical recorded data from 1948-2011 for Clemson, SC are shown in Figure 3. The data shows significant year to year variation in the historical recorded data and a similar level of variation across the different GCM data sets presented. There is also a steady increase in the GCM predicted ATR over time. This is seen more clearly in Figure 4 which shows the mean and standard deviation of the historical data along with the yearly mean and standard deviation from the 134 GCM data sets. Note that there is a slight jump in average ATR from the historical mean to the start of the GCM time series. However, this discontinuity is well within the range of variability observed in both the historical and GCM projected data.

The downscaled GCM data shows a clear increase in the ATR over time. However, a histogram of the ATR from 2089-2099 for each of the 134 GCMs shows only a slight increase in mean ATR compared to historical records (see Figure 5). To verify that the increase is statistically significant a T-test was performed to compare the historical data with the GCM data for the last eleven years of the century (20892099). The T-test showed that the difference in the means

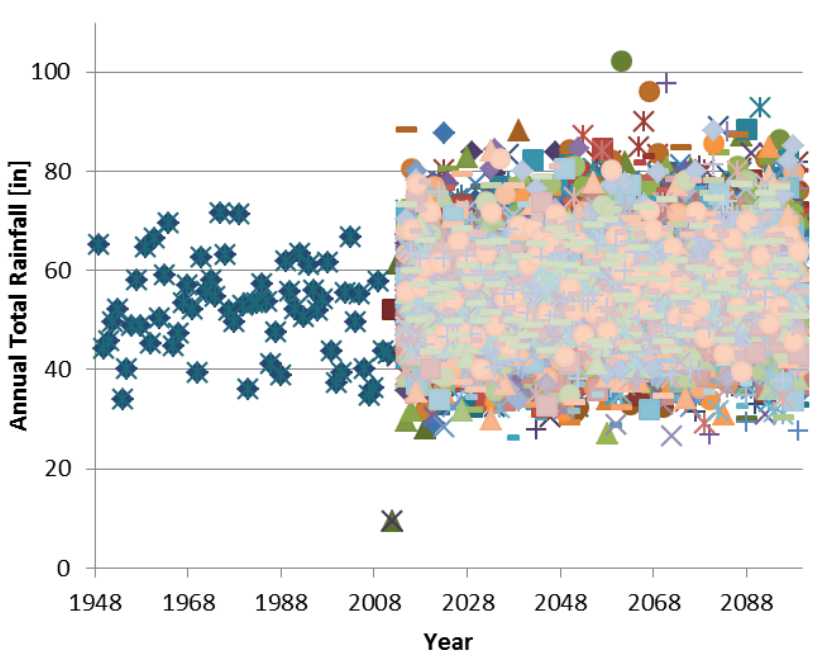

Figure 3. NOAA observed historical annual total rainfall (19482011) and predicted annual total rainfall (2015-2099) from 134 different realizations of GCMs for Clemson, SC. 


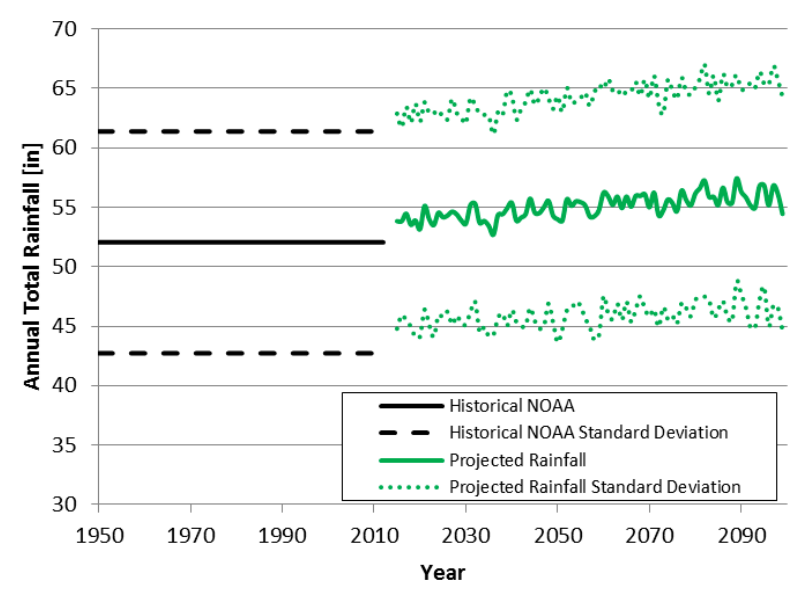

Figure 4. Averaged ATR for Clemson, SC based on NOAA observed data (1950-2011) and projected rainfall for 2015-2099 based on 134 realizations of GCMs.

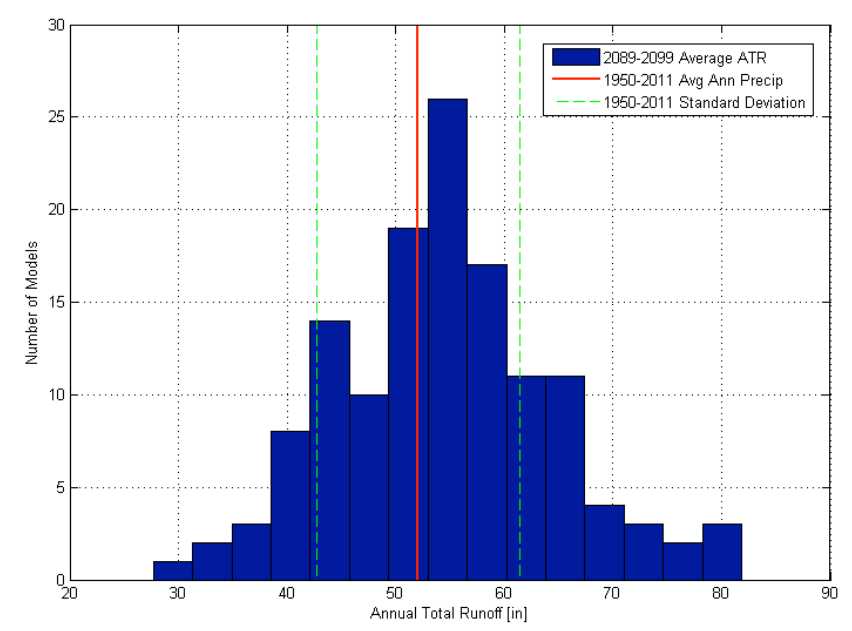

Figure 5. Histogram of the average ATR for Clemson, SC from 2089 to 2099 based on 134 downscaled realizations of GCM data sets. The vertical line represents the current average ATR.

was statistically significant with a $97.5 \%$ confidence interval.

The data and analysis above was for a single location, Clemson, SC. Similar analysis was conducted for each of the precipitation gauge locations throughout the state. All locations showed an increase in ATR between 2015 and the end of the century. However, the net increase in ATR historical mean and standard deviation in ATR was compared to the mean and standard deviation of the ATR for 2015 based on all 134 GCM realizations. These data varied across the state. There was also an offset between the predicted 2015 mean ATR based on 134 GCM data sets and the historical record. At each gauge location the ATR is compared to historical values, which are plotted in Figure 6 and Figure 7. Figure 6 shows a scatter plot of historical mean ATR versus 2015 GCM mean ATR. The offset between the historical mean and the 2015 mean varies by location though the 2015 GCM mean ATR is almost always larger than the historical mean ATR. This would be expected for a climate with increasing mean ATR as the historical record would average over a non-

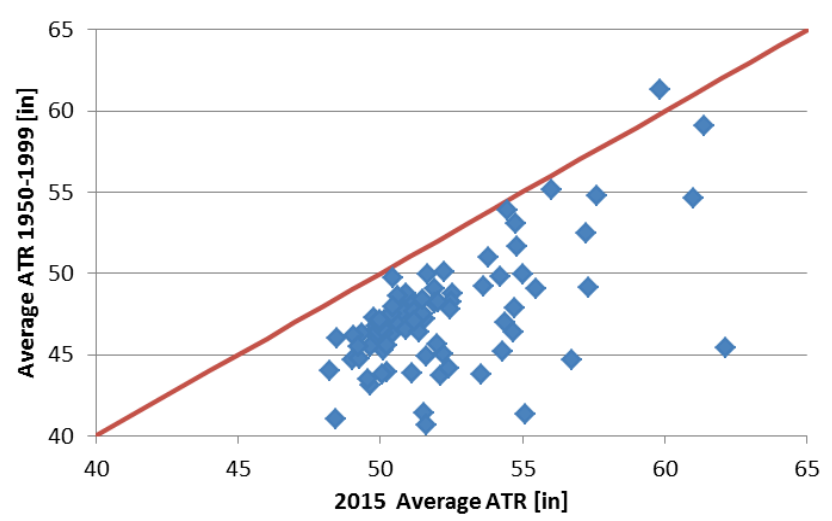

Figure 6. Scatter plot of 2015 GCM mean ATR versus historical average ATR for 1950-1999 with the red line showing exact agreement. Each data point represents a station.

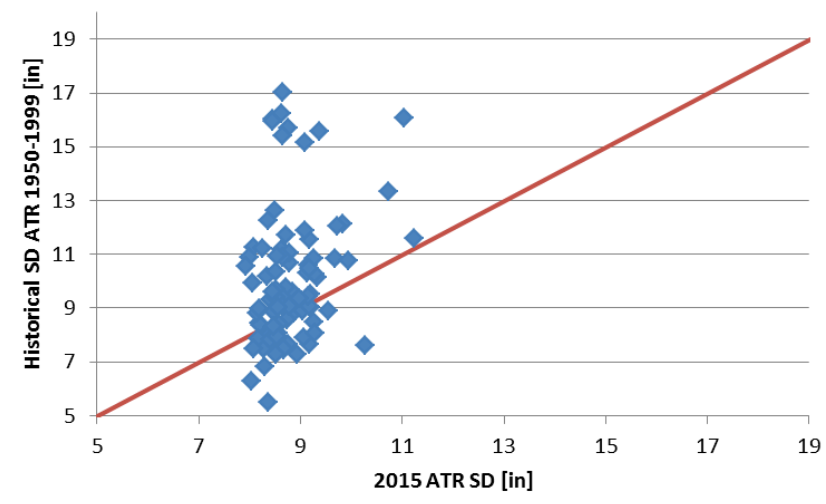

Figure 7. Scatter plot of 2015 GCM SD of ATR versus historical average ATR with the red line showing exact agreement. Each data point represents a station.

stationary data set and would, therefore, underestimate the current mean ATR. Figure 7 shows the standard deviation in the historical ATR versus the 2015 GCM ATR standard deviation. Again the difference varies with location though in this case the standard deviation is not consistently higher or lower for the GCM data. The historical data shows a greater range of standard deviations compared to the GCM data, though this is likely due to the smaller number of data points in the historical data sets used in this analysis (average 41 years of data, 14 year standard deviation) compared to the 134 data points for the 2015 GCM ATR standard deviation.

Given the variation in both mean offset and predicted standard deviation it might be somewhat misleading to simply present the difference between the historical mean and the mean averaged over the later years of the century. Instead, we present data for the projected change in ATR based on a linear curve fit through the mean ATR for the GCM data from 2015-2099. Straight lines were fitted through the mean GCM ATR for each location. The slope of this line (with units of in/year) was then multiplied by 84 years (the GCM POR) to give a projected change in ATR over the remainder of the century. The data from each station was then entered into ArcGIS by ESRI where the geographic data information 


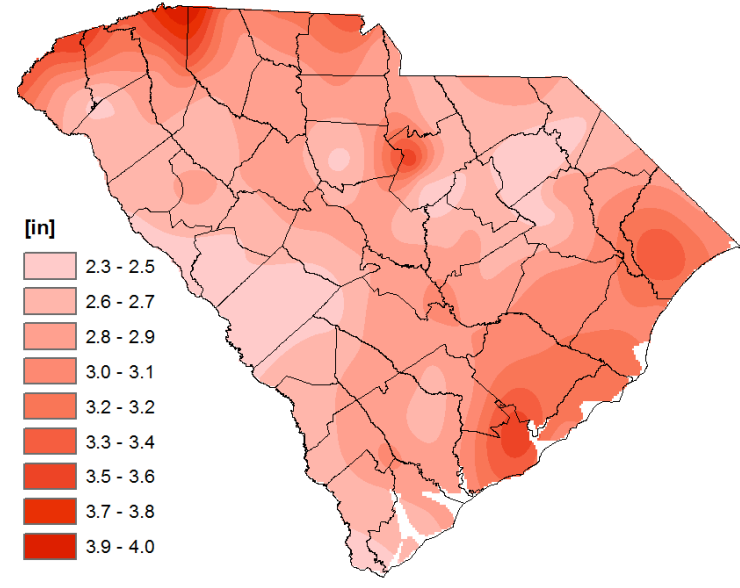

Figure 8. GCM simulations of change in average ATR (inches) over the forecast period (2015-2099) using the ATR trendline slope.

was interpolated using a tensioned spline method to create contour surfaces. A tension spline interpolation results on a surface that is less smooth but more closely constrained by the inputted data. This contour plot is presented in Figure 8.

Figure 8 shows significant variation in ATR change from 2.3 in for certain parts of the Savannah River basin to over 3.5 in in the coastal region, especially Charleston and Horry County. Much of the upstate and the length of the Savannah River Basin are all predicted to see lower levels of ATR increase compared to the rest of the state. The exception to this is the northern section of the border between Greenville and Spartanburg counties which will see ATR increases of around 4 in.

\section{Changes in 24-Hour Design Storm Depths}

Stormwater design in South Carolina is generally based on the 2, 10, and 100 year return period storms (DHEC 2002). Therefore, it is important to see how these design storm depths change over time, especially in comparison to the current NOAA return period data. In a changing climate the idea of a return period storm is not clearly defined. However, given 134 annual time series per year it is possible to get reasonable estimates of 2, 5, 10, 25, 50, and 100 year return period 24 hour storm depths for each year in the GCM POR and analyze how they change over time. A sample plot of the variation in storm depth for Clemson, SC is shown in Figure 9 along with the current NOAA values for the same return periods.

As with the ATR, the 24-hour storm depths are also seen to increase over time for each return period. However, there is also a difference between the historical record and the 2015 GCM projection for the each return period storm. In this case, the 2015 GCM data is lower than the NOAA value for the 2 year storm and higher than the NOAA value for the 100 year storm. In general the 2015 GCM projections for the 100 year storm were higher than current NOAA values though not always. Figure 10 shows a histogram of this difference for the 101 precipitation gauges analyzed as part of this study. The vast majority of locations have a difference of less than 1 in though some exhibit differences of up to 4

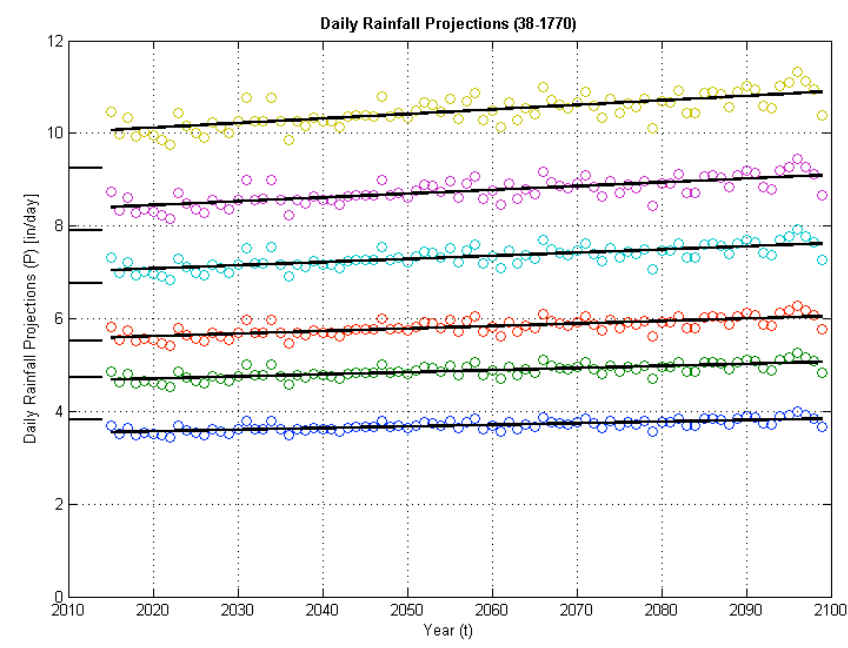

Figure 9. Forecast of storm depths versus year based on 134 downscaled GCM data sets. 100, 50, 25, 10, 5, and 2 year storm depth are shown from top in descending order. The horizontal lines on the $y$-axis show the current NOAA value for the respective storm depth. The solid lines through the data are linear best fits to the data.

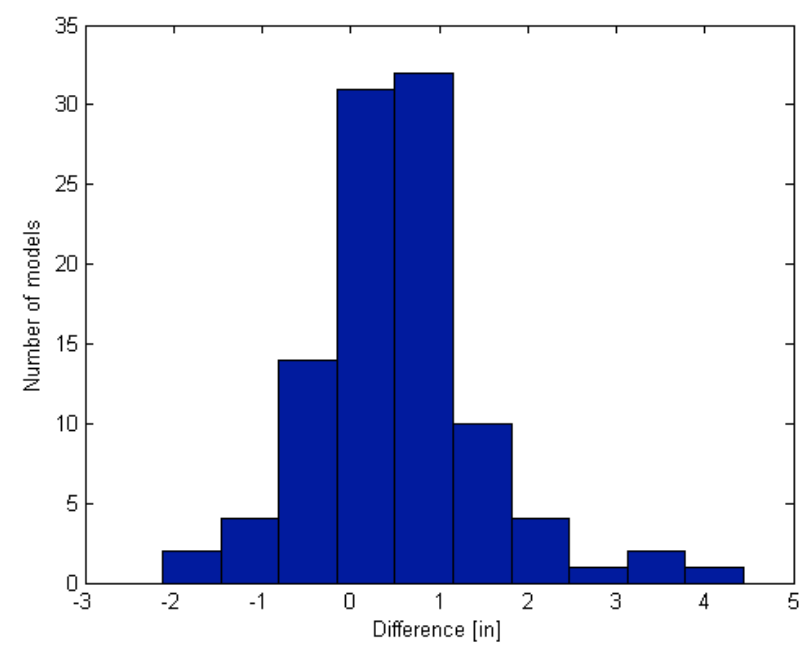

Figure 10. Histogram of the difference between the linear trend line value for the 2015 GCM 100 year storm depth and the current 100 year storm depth reported by NOAA for all 101 stations analyzed.

in. Twenty stations had 2015 GCM 100 year 24 hour storm depths lower than the current NOAA data. Regardless of the offset between 2015 GCM predictions and current NOAA data there is a clear upward trend in all six return period storm depths. Therefore, as with the ATR data, the projected change in depth is reported. Lines were fitted through the yearly return period depths for each return period and each precipitation gauge. The slope of these lines was then used to calculate the projected increase in storm depth by the end of the century across the state.

As with the mean ATR, there is significant uncertainty in the calculated values of 24 hour storm depth for a given return period. As such, NOAA reports the calculated depth and the depths at the extremes of the $90 \%$ confidence interval. For each rain gauge location, the projected year at which 
the GCM calculated storm depth exceeded the upper range of the $90 \%$ confidence interval for the historical data was calculated. Histograms of this year for each of the calculated return period storms are shown in Figure 11.

The data shows that there is a larger change in the longer return period storms. For example, most locations will not see the 2-year storm depth exceed the current NOAA 90\% confidence interval value until well into the next century whereas most locations will have 100-year storm depths that exceed the current $90 \%$ confidence interval in the next few years. The year in which the GCM trendline exceeds the current $90 \%$ confidence interval is sometimes greatly outside the simulation period of record and should, therefore, not be taken as predictive. However, the data clearly shows that longer return period storms will exceed the current $90 \%$ confidence interval sooner than smaller storms.

The linear fits for each location and each return period were used to create contour plots of the total change in depth predicted over the GCM POR. The slope of each line was multiplied by 84 (the number of years in the POR) to calculate a change in depth. This approach is the same as that used for calculating changes in mean ATR over the GCM POR and ignores any offset between the 2015 GCM data and historical data. This offset is discussed below. A contour plot of the projected depth change for each return period storm is shown in Figure 12. The GCM data projects that the 100 year storm depth will increase by between 0.5 in and 1.2 in over the next 84 years whereas the 2 -year storm depths only increase by between 0.2 and 0.5 in. As with the ATR data there is significant variation across the state with the largest increases in similar regions to those that were predicated to have the largest increase in ATR.

One possible explanation for the 2015 GCM 100 year storm depth being different, and typically deeper, from the current NOAA data is that the climate has already been changing over time. If this is the case, and the extreme event depths have been increasing over time, then there should be a correlation between the GCM 2015 to NOAA difference and the projected change in 100 year storm depth as plotted in Figure 12. Figure 13 shows a contour plot of the GCM 2015 to NOAA difference for the entire state. Visual comparison between Figure 12 and Figure 13 indicates that the regions of higher storm depth growth (darker regions of Figure 12) correspond to regions of greater initial difference in depth (darker regions of Figure 13). Further evidence of this relationship is shown in Figure 14 which shows scatter plots of the initial difference versus projected change for each of the return periods considered. Again, a clear correlation is observed between the offset and the projected rate of increase in storm depth.

\section{DISCUSSION}

A detailed analysis of the projected change in rainfall patterns in South Carolina has been conducted using BCCA downscaled GCM data from CMIP5. The GCM data show that average total annual rainfall will increase across the state over the remainder of the century. However, the increase is not uniform across the state with coastal regions predicted to have greater increases than most of the state. The Savannah River Basin is predicted to have below average growth in average annual total rainfall compared to the rest of the state. While the trend toward increasing ATR is clear in the data, the increase is quite small compared to typical year to year variability (see Figure 5).

The analysis also shows that the 2, 5, 10, 25, 50, and 100 year 24-hour design storm depths will all increase across the state over the remainder of the century. For example, the 100 -year design storm depth is projected to increase between 0.5 and 1.2 inches across the state by 2099. In fact the GCM projections for 100 year return period 24 hour storm depths for most of the state will exceed the current NOAA $90 \%$ confidence interval in the next few years. However, the 2-year 24 hour storm depth will not exceed the NOAA 90\% confidence interval until well into the next century for most locations in the state.

For both the ATR and the 24 hour storm depths there was an offset between the projected 2015 values and the historical data. In almost all cases the 2015 GCM ATR was greater than the historical mean though well within historical levels of variability. The offsets between the current NOAA 24-hour storm depth data and the projected 2015 GCM values were quite varied. A substantial number of the offsets were negative indicating that the GCM storm depths were below the historical calculated values. However, the increase in storm depth over time was clear for every return period throughout the state. Further, the offset between the GCM and historical data was shown to be correlated to the local rate of change in the projected storm depths (see Figure 14). In general, the longer the return period of the storm, the greater the rate of increase in storm depth and the sooner the storm depth is predicted to exceed the current NOAA $90 \%$ confidence interval upper value.

\section{CONCLUSION}

The projected increases in both average annual total rainfall and design storm depths have the potential to stress existing stormwater infrastructure. The increases may also require regulatory agencies to re-visit their published design storm depths. One possible approach to mitigating the impact of these changes is to require new developments, as well as re-developments and retro-fits, to more closely replicate the predevelopment site hydrology. This could be done through the use of low impact development (LID) best management practices (BMP) to encourage infiltration and on-site runoff management. Such an approach has the potential to make new development more resilient to the projected changes in rainfall patterns. 

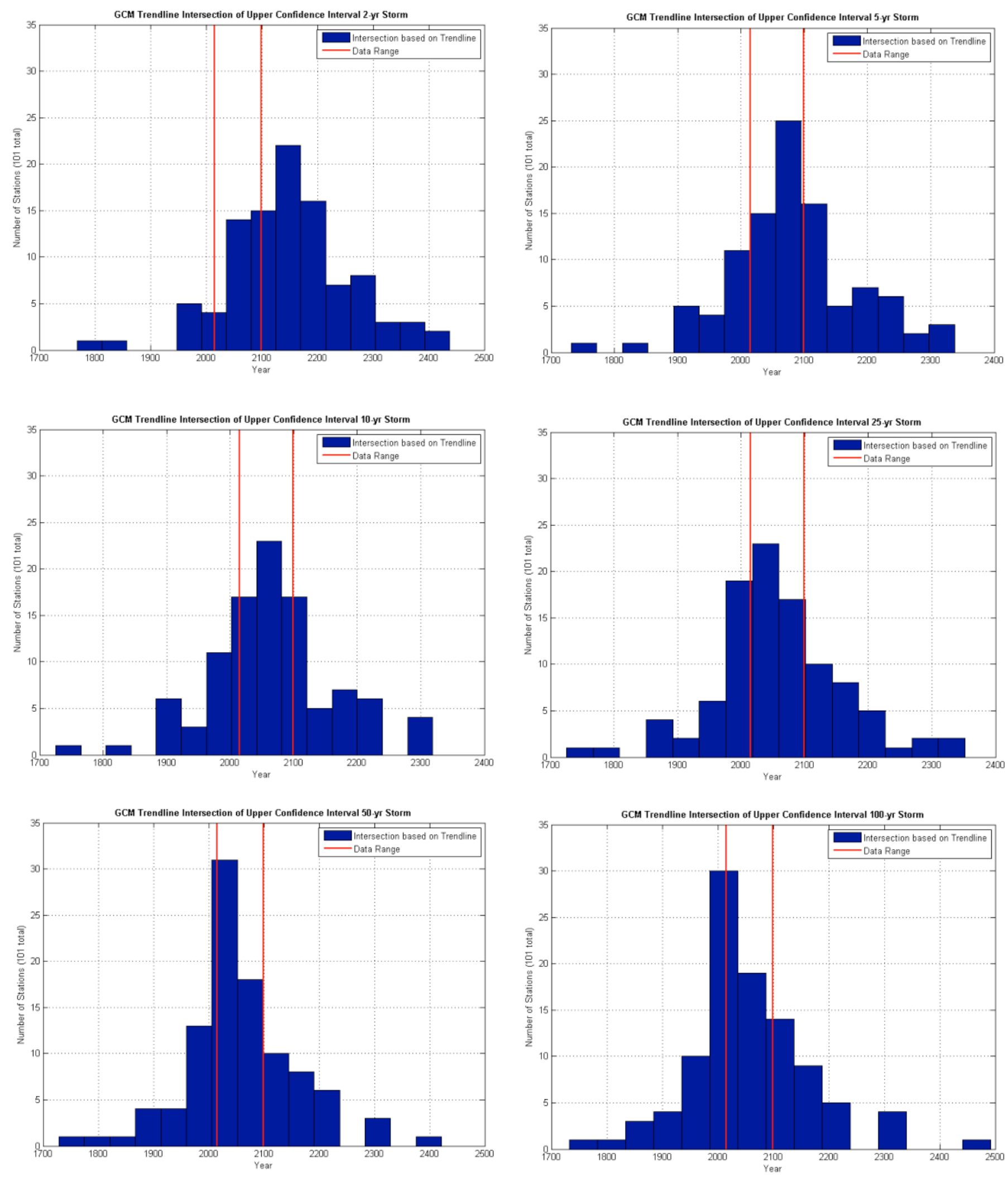

Figure 11. Histograms of the year in which the 24 hours storm depth will exceed the current NOAA $90 \%$ confidence interval upper limit using the GCM trendline equation. Reading from top and left to right, 2, 5, 10, 25, 50, and 100 year return period storms. The vertical red lines represent the GCM simulation POR. 

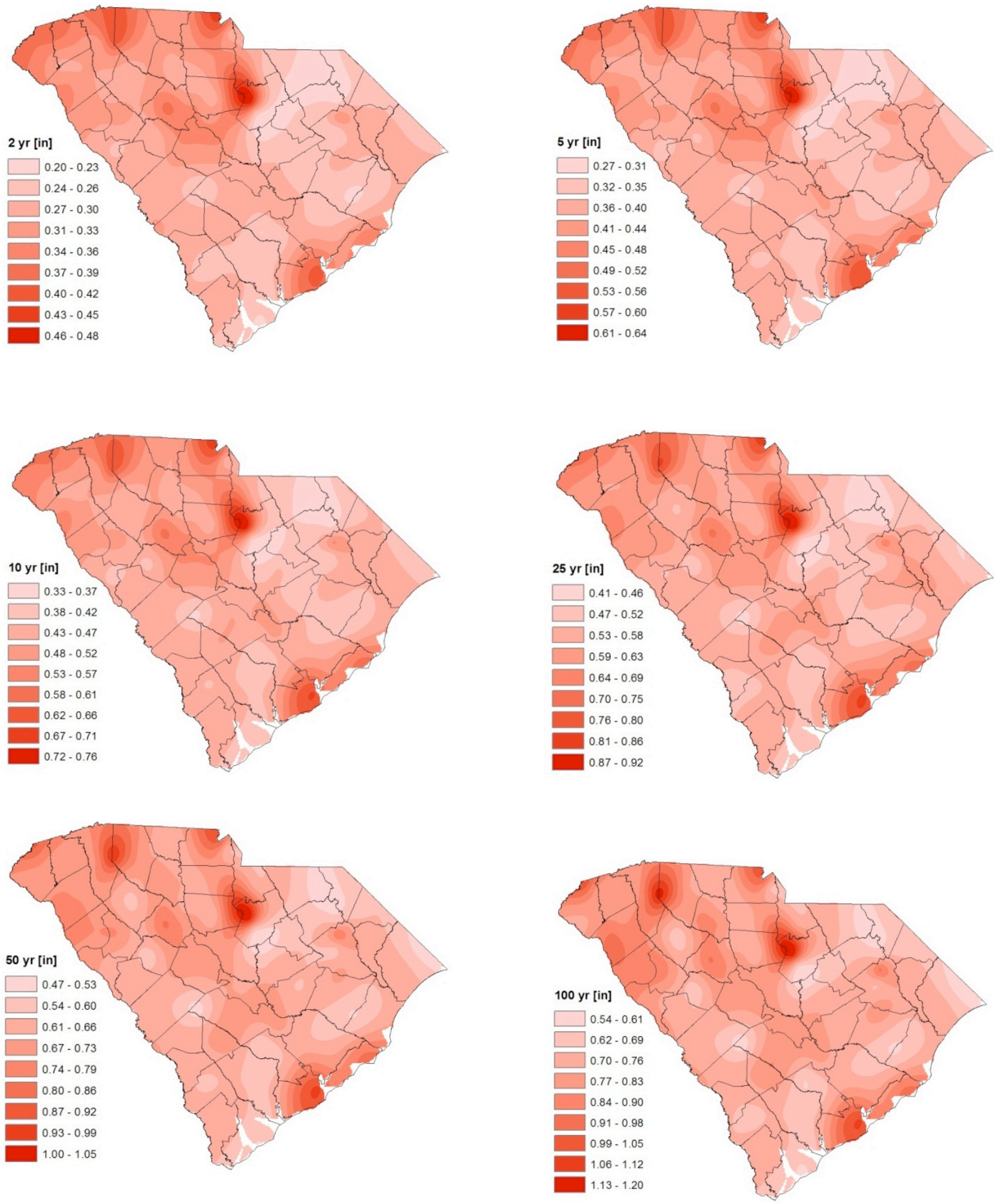

Figure 12. Contour plot of the GCM prediction of the change in 24 hour design storm depth (inches) over the forecast period. Reading from top and left to right, 2, 5, 10, 25, 50, and 100 year return period storms. 


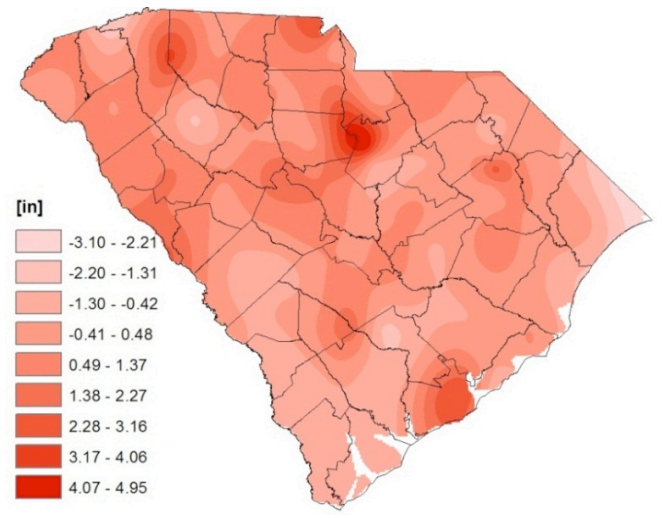

Figure 13. Contour plot of the offset between the 2015 GCM 100 year storm and the current NOAA data.
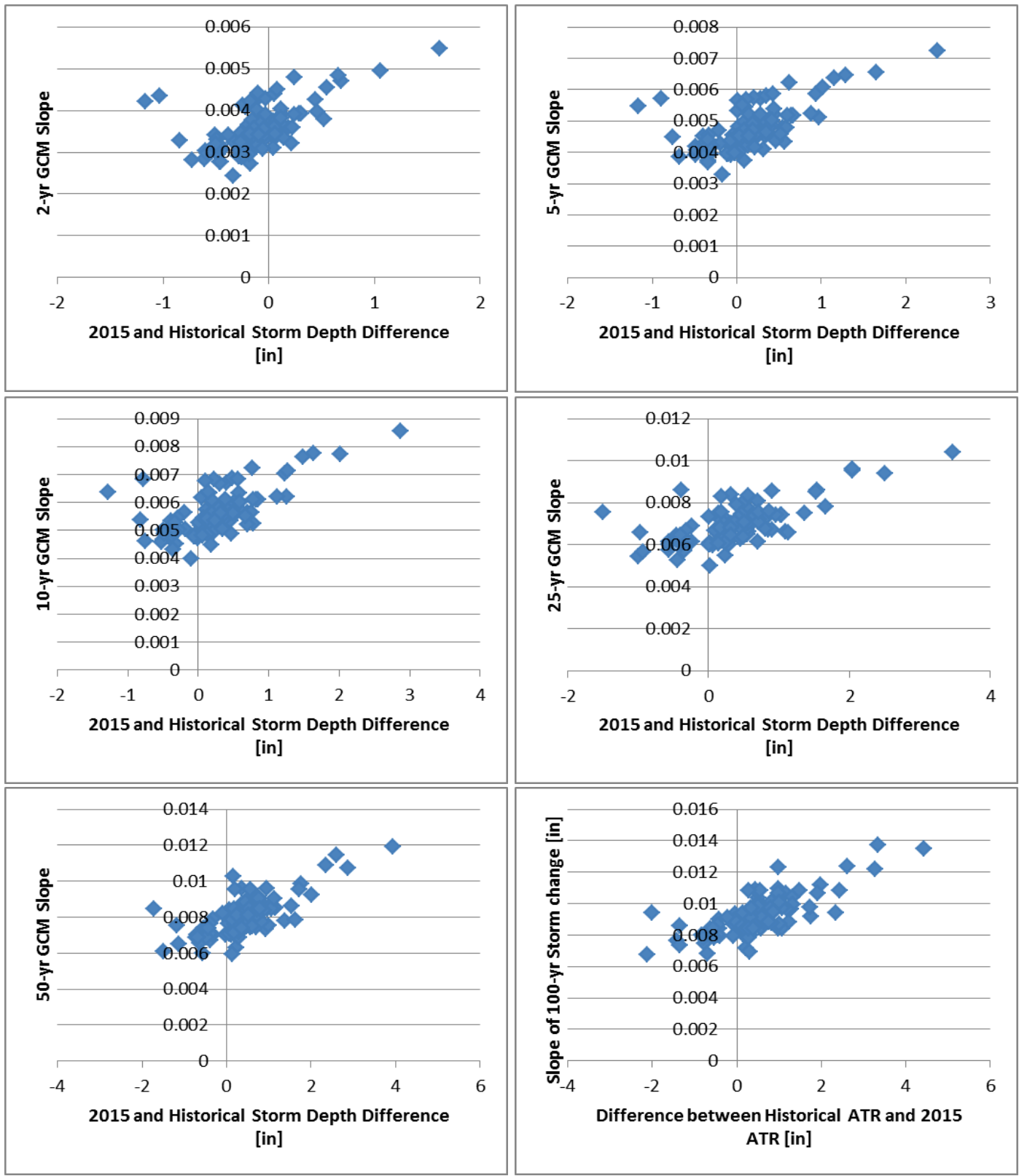

Figure 14. Scatter plot of the offset between the 2015 GCM 24 hour storm depth and the current NOAA data versus the projected growth in storm depth over the next 84 years. Reading from top and left to right, 2, 5, 10, 25, 50, and 100 year return period storm. 


\section{LITERATURE CITED}

Ahmed, K. F., G. Wang, J. Silander, A. M. Wilson, J. M. Allen, R. Horton, and R. Anyah, 2013. Statistical downscaling and bias correction of climate model outputs for climate change impact assessment in the U.S. northeast. Global and Planetary Change 100:320-332.

Barsugli, J., C. Anderson, J. Smith, and J. Vogel, 2009. Options for Improving Climate Modeling to Assist Water Utility Planning for Climate Change. Water Utility Climate Alliance.

Bonnin, G., D. Martin, B. Lin, T. Parzybok, M. Yekta, and D. Riley, 2006. Precipitation-Frequency Atlas of the United States NOAA Atlas 14, 2:3.0.

Brekke, L., M. Dettinger, E. Maurer, and M. Anderson, 2008. Significance of model credibility in estimating climate projection distributions for regional hydroclimatological risk assessments. Climate Change 89:371-394.

Brown and Wilby, 2012. An Alternate Approach to Assessing Climate Risks. Eos, 92:41:401-402.

Department of Health and Environmental Control (DHEC). Bureau of Water, 2002. Standards for Stormwater Management and Sediment Reduction, Regulation 72-300. IPCC, 2014. Climate Change 2014 Synthesis Report. Summary for Policymakers. [Accessed 07-12-14] http:// www.ipcc.ch/pdf/assessment-report/ar5/syr/SYR_AR5 SPMcorrl.pdf.

IPCC, 2001. Climate Change 2001. The Scientific Basis. [Accessed 07-11-14] http://www.ipcc.ch/ipccreports/tar/ wg1/pdf/WG1_TAR-FRONT.PDF.

Martinez, Maleski, and Miller, 2012. Trends in precipitation and temperature in Florida, USA. Journal of Hydrology 452-453:259-281.

Maurer, E. and H. Hidalgo, 2008. Utility of daily vs. monthly large-scale climate data: an intercomparison of two statistical downscaling methods" Hydrol. Earth Syst. Sci., 12:551-563.

Mishra and Lettenmaier, 2011. Climatic trends in major U.S. urban areas, 1950-2009. Geophysical Research Letters 38:L16401.

U.S. Department of the Interior, Bureau of Reclamation Reclamation, 2014. 'Downscaled CMIP3 and CMIP5 Climate and Hydrology Projections: Release of Hydrology Projections, Comparison with preceding Information, and Summary of User Needs', prepared by the, Technical Services Center, Denver, Colorado. 110 pp. 